\title{
Optical calibration facility at the Izaña Atmospheric Research Center
}

\section{Laboratorio de calibración óptica del Centro de Investigación Atmosférica de Izaña}

\author{
C. Guirado(1,2,*), R. Ramos(2), Á. de Frutos(1,S), A. Berjón(1,3,S), A. Redondas(2), C. López(4), \\ V. Cachorro(1,S), E. Cuevas(2), R. González(1), S. González(1), M. Hernández(4) \\ 1. Atmospheric Optics Group, Valladolid University (GOA-UVA), Spain. \\ 2. Izaña Atmospheric Research Center, Meteorological State Agency of Spain, AEMET, Spain. \\ 3. Laboratoire d'Optique Atmosphérique, Université Lille, France.
}

4. Sieltec Canarias SL, Spain.

(") Email: cguiradof@aemet.es

S: miembro de SEDOPTICA / SEDOPTICA member

Recibido / Received: 30/01/2011. Aceptado / Accepted: 30/08/2011.

\begin{abstract}
:
During the last years a new optical calibration facility has been developed and deployed at the Izaña Observatory for the calibration and characterization of the radiation measuring instruments within research activities. These activities require a traceable Quality Assurance \& Quality Control system. This new facility allows the absolute, spectral and cosine response calibration. At present there are six set-ups running at the laboratory for radiance calibration, angular response determination, spectral response characterization, slit function determination and absolute irradiance calibration (vertical and horizontal set-ups). Each method and procedure has required the development of the corresponding protocol. These systems, as well as some examples of instrument calibrations, are presented in this work.
\end{abstract}

Keywords: Calibration Facility, Quality Assurance, Quality Control, Radiation, Izaña.

\section{RESUMEN:}

Durante los últimos años ha sido implementado un nuevo laboratorio de calibración óptica en el Observatorio de Izaña para la caracterización de los instrumentos de medida de radiación, en el marco de actividades de investigación que requieren un estricto control de calidad de las medidas realizadas. Esta nueva instalación dispone de diversos dispositivos para la calibración absoluta, espectral y de respuesta coseno de los instrumentos radiométricos mencionados anteriormente. En este momento hay seis sistemas funcionando en el laboratorio que permiten la calibración en radiancia, el cálculo de la respuesta angular, la caracterización de la respuesta espectral, la determinación de la función rendija y, dos de ellos, la calibración absoluta en irradiancia (tanto en posición horizontal como vertical). Cada procedimiento o método de calibración ha requerido la realización del correspondiente protocolo. En este artículo se realiza una descripción de cada dispositivo y se muestran algunos ejemplos de calibración instrumental.

Palabras clave: Laboratorio de Calibración, Control de Calidad, Radiación, Izaña.

\section{REFERENCIAS Y ENLACES / REFERENCES AND LINKS}

[1]. http://www.pmodwrc.ch/euvc/euvc.php?topic=calibration services

[2.] H. Slaper, P. den Outer, Analysis of spectral wavelength shifts, spectral anomalies, spectral resolution and calculation of weighted UV-doses by means of the software package SHICrivm, User Guide version 3.075, July 2002 


\section{Introduction}

The high altitude Izaña Atmospheric Observatory (IZO) is engaged in several national and international atmospheric and environmental research networks and programs (i.e. GAW, BSRN, AERONET, NDACC, RBCC-E) in which is crucial a robust and traceable quality assurance and quality control (QA/QC) system for the different broad band radiometers, photometers and spectrometers which measure, among other parameters, spectral solar radiation, aerosol optical depth and total ozone amount. For this reason a new optical calibration facility is available at the Izaña Observatory.

The new set-ups of the optical calibration facility developed at the Izaña Observatory are the result of a joint effort of the Izaña Atmospheric Research Center (IARC-AEMET) and the Atmospheric Optics Group of Valladolid University (GOA-UVA). The six set-ups running at present in an isolated dark room at IZO have being designed for determination of the absolute (radiance and irradiance), spectral and cosine response calibration of the radiation measuring instruments installed on the roof of the Izaña Observatory.

All of the calibration systems account for the different specific requirements of each sensor to be calibrated depending on its physical features as shape, size and weight. The set-ups have been built in a modular way, and the control and acquisition software have been developed such way the calibration facility could be easily adapted and meet the specific requirements of each program. Each calibration method and procedure has required the development of the corresponding written protocol.

Each one of the calibration systems are described in Section 2 and several instrument calibration examples are presented in Section 3

\section{Calibration set-ups}

\section{2.a. Absolute irradiance calibration}

There are two different systems for the absolute irradiance calibration.

One of them has been designed for the calibration of the instruments in a horizontal oriented position (Fig. 1). The holders for the light source, the sensor to be calibrated and the rest of the components of the set-up are placed on an optical bench making it easier to align the system. Mainly this system is used for calibration of the radiometers belonging to the Baseline Surface Radiation Network at Izaña.

However there are big and heavy instruments, such as the Brewer spectrophotometer, that can not be calibrated in that horizontal oriented position. That is the reason why a second absolute irradiance calibration system has been developed allowing the calibration in a vertical oriented position (Fig. 2). The degrees of freedom of this set-up are more than in the horizontal system, so the

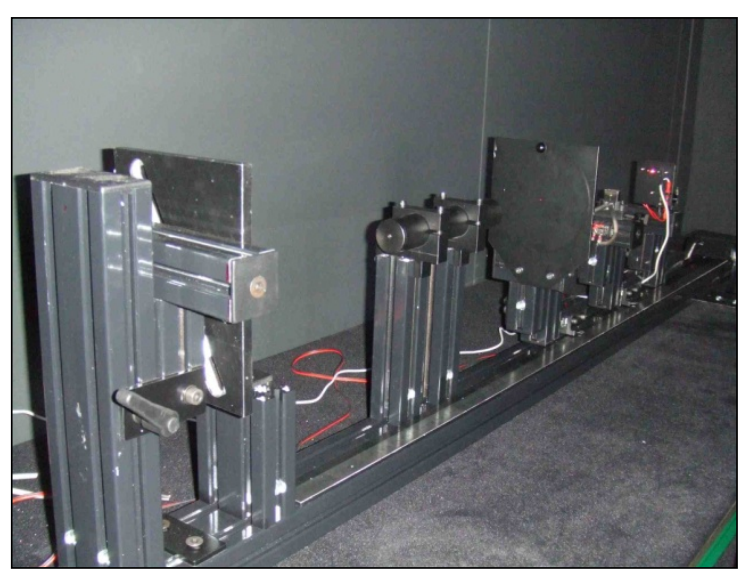

Fig. 1. Horizontal absolute irradiance calibration set-up.

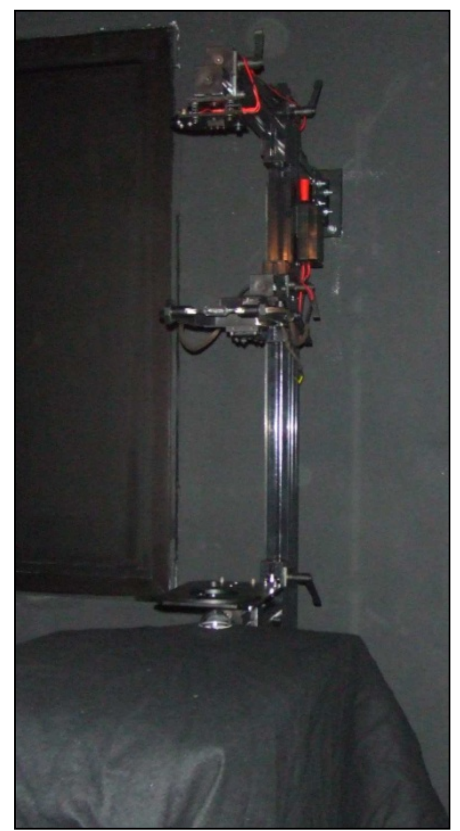

Fig. 2. Vertical absolute irradiance calibration set-up. 
alignment of the system is slightly more difficult. Therefore the horizontal set-up is used to calibrate the smaller instruments (pyranometers and multifilter radiometers) while the larger ones (Brewer and Bentham spectrometers) are calibrated using the vertical set-up.

The basis of the absolute irradiance scale consists on a set of DXW-type $1000 \mathrm{~W}$ lamps (for vertical set-up) and $1000 \mathrm{~W}$ FEL lamps (for horizontal set-up) traceable to the primary irradiance standard of the PhysikalischTechnische Bundesanstalt (PTB). The accuracy of the current intensity of the lamp during the calibration and the distance between the optical entrance of the instrument and the lamp are tightly controlled.

\section{2.b. Absolute radiance calibration}

This system has been developed for the instruments which perform sky radiance measurements as the Cimel sun photometers of the AERONET-PHOTONS-RIMA networks (Fig. 3).

The light source for the radiance calibration comes from an integrating sphere wich provides a spatially integrated radiant flux. Its calibration certificate is traceable to the National Institute of Standards and Technology (NIST) and three times a year a recalibration of the sphere is accomplished by comparison to the travel Master Cimel sun photometer of the National Aeronautics and Space Administration (NASA). The accuracy of the calibration is dependent on the stability of the radiance emission and the alignment between the sphere and the detector to be calibrated.

\section{2.c. Angular response calibration}

The irradiance measurements require the detector to weight incoming radiation with the cosine of the incoming angle relative to normal incidence [1]. This set-up (Fig. 4) is used to quantify the deviations from an ideal cosine response of radiometer and spectrophotometer measurements.

The relative angular response function is measured rotating the mechanical arm where the seasoned DXW-type $1000 \mathrm{~W}$ lamp is located. The rotation is controlled by a stepper motor with $0.01^{\circ}$ of precision. Rotation over $360^{\circ}$ is possible but only $\pm 90^{\circ}$ of rotation is used for the calibration while the instrument is illuminated by the uniform and parallel light beam of the lamp.

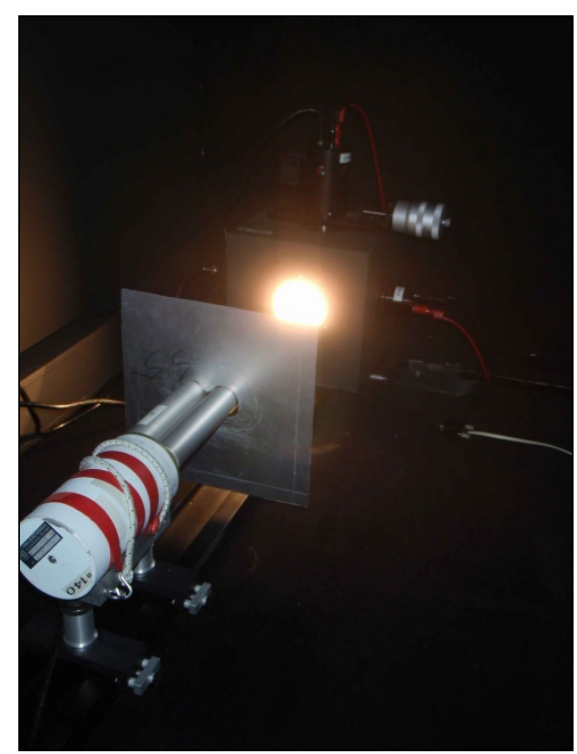

Fig. 3. Radiance calibration set-up with a cimel sunphotometer.



Fig. 4. Angular response function set-up with a YES UVB-1 pyranometer. 


\section{2.d. Spectral response calibration}

Radiation measurements with broadband filter radiometers fundamentally depend on the relationship between the measured radiation spectrum and the spectral responsivity of the radiometer [1].

The relative spectral response set-up consists of an Optronic double monochromator OL 750 (Fig. 5). The wavelength can be selected through three gratings within the range 200 to $1100 \mathrm{~nm}$ with a precision of $0.1 \mathrm{~nm}$. An OL 740-20 light source (Fig. 5) positioned in front of the entrance slit acts as radiation source and two lamps, UV (200-400 nm) and tungsten (250$2500 \mathrm{~nm}$ ) are available.

\section{2.e. Slit function determination}

Differences in the slit function, particularly in the Full Width at Half Maximum (FWHM), cause a reproducible spectral noise when spectra from different instruments are compared. Deconvolution techniques can, at least partly,

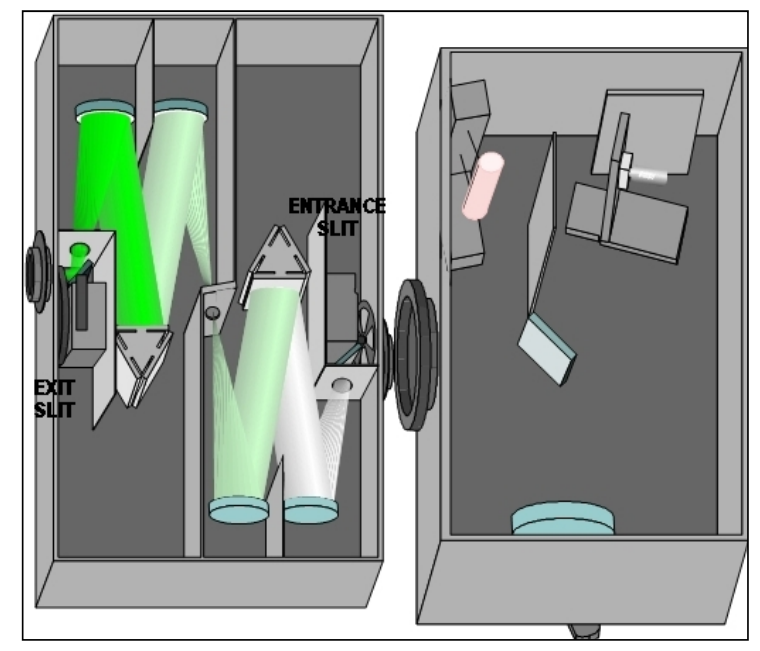

Fig. 5. Scheme of the Optronic OL 750 and light source.



Fig. 6. Slit function determination set-up. account for these problems in comparing data from different instruments [2]. The deconvolution of a measured spectrum is performed using the slit function of the instrument or, at least, its FWHM.

At the laboratory the slit function calculation is done illuminating the entrance slit of instruments, such as Brewer and Bentham spectrometers, with the monochromatic light of a VM-TIM He-Cd laser (Fig. 6). The nominal wavelength of the laser is $325 \mathrm{~nm}$, its power is 6 $\mathrm{mW}$, and its beam diameter is $1,8 \mathrm{~mm}$.

\section{Several radiance and irradiance calibrations developed at the Optical Calibration Facility of Izaña}

\section{3.a. Absolute radiance calibration of the Cimel sunphotometer \#380}

The results of the calibration of the Cimel\#380 performed on September 11th, 2009 are shown here as an example (Fig. 7). Two measurements in the morning and two ones in the afternoon were performed. The aureole and the sky calibration are taken as valid ones when the standard deviation of all the measurements is less than $1 \%$ (Tables I and II). The files containing the calibration factors are submitted to AERONET (Aerosol Robotic Network, http://aeronet.gsfc.nasa.gov/) and are used until the next calibration.

\section{3.b. Absolute Irradiance Calibration of the Brewer spectrophotometer \#201}

The results of the calibration of the Brewer\#201 performed on March 10th, 2010 are shown in Fig. 9. The intensity and the voltage applied to the lamp (Fig. 8) and several parameters of the spectrophotometer were checked during the calibration.

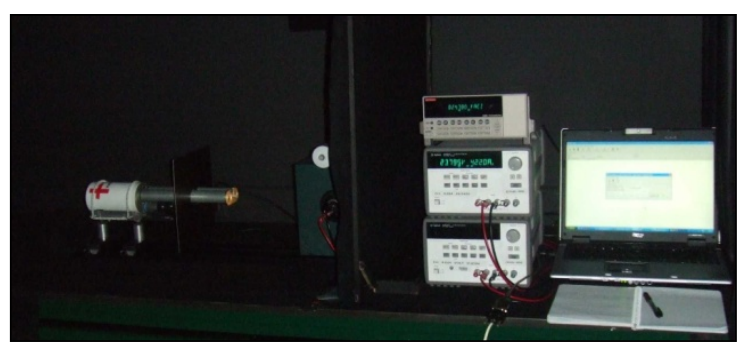

Fig. 7. Radiance calibration of the Cimel\#380. 
TABLE I

Aureole radiance calibration factors

\begin{tabular}{|c|c|c|c|c|}
\hline Time & $\mathbf{1 0 2 0} \mathbf{~ n m}$ & $\mathbf{8 7 0} \mathbf{~ n m}$ & $\mathbf{6 7 0} \mathbf{n m}$ & $\mathbf{4 4 0} \mathbf{n m}$ \\
\hline $9: 48: 31$ & 0.019529 & 0.014046 & 0.019755 & 0.033614 \\
\hline $9: 58: 14$ & 0.019497 & 0.014035 & 0.019741 & 0.033593 \\
\hline $14: 39: 04$ & 0.019396 & 0.014002 & 0.019711 & 0.033542 \\
\hline $14: 51: 16$ & 0.019361 & 0.01399 & 0.019695 & 0.033506 \\
\hline Mean & $\mathbf{0 . 0 1 9 4 4 6}$ & $\mathbf{0 . 0 1 4 0 1 8}$ & $\mathbf{0 . 0 1 9 7 2 6}$ & $\mathbf{0 . 0 3 3 5 6 4}$ \\
\hline St Dev(\%) & $\mathbf{0 . 4 1 1 5 5 9}$ & $\mathbf{0 . 1 8 9 3 0 8}$ & $\mathbf{0 . 1 3 8 8 6 7}$ & $\mathbf{0 . 1 4 5 8 4 6}$ \\
\hline
\end{tabular}

TABLE II

Sky radiance calibration factors

\begin{tabular}{|c|c|c|c|c|}
\hline Time & $\mathbf{1 0 2 0} \mathbf{~ n m}$ & $\mathbf{8 7 0} \mathbf{~ n m}$ & $\mathbf{6 7 0} \mathbf{n m}$ & $\mathbf{4 4 0} \mathbf{n m}$ \\
\hline $9: 48: 31$ & 0.004445 & 0.002957 & 0.004017 & 0.008079 \\
\hline $9: 58: 14$ & 0.004437 & 0.002955 & 0.004014 & 0.00807 \\
\hline $14: 39: 04$ & 0.004407 & 0.002947 & 0.004002 & 0.008046 \\
\hline $14: 51: 16$ & 0.004398 & 0.002946 & 0.003998 & 0.008038 \\
\hline Mean & $\mathbf{0 . 0 0 4 4 2 2}$ & $\mathbf{0 . 0 0 2 9 5 1}$ & $\mathbf{0 . 0 0 4 0 0 8}$ & $\mathbf{0 . 0 0 8 0 5 8}$ \\
\hline St Dev(\%) & $\mathbf{0 . 5 1 4 8 4 4}$ & $\mathbf{0 . 1 8 8 4 0 4}$ & $\mathbf{0 . 2 2 9 0 2 6}$ & $\mathbf{0 . 2 4 0 7 1 2}$ \\
\hline
\end{tabular}

Finally the ultraviolet response was calculated (Fig. 9) to apply it to the UV radiation measurements of this instrument.

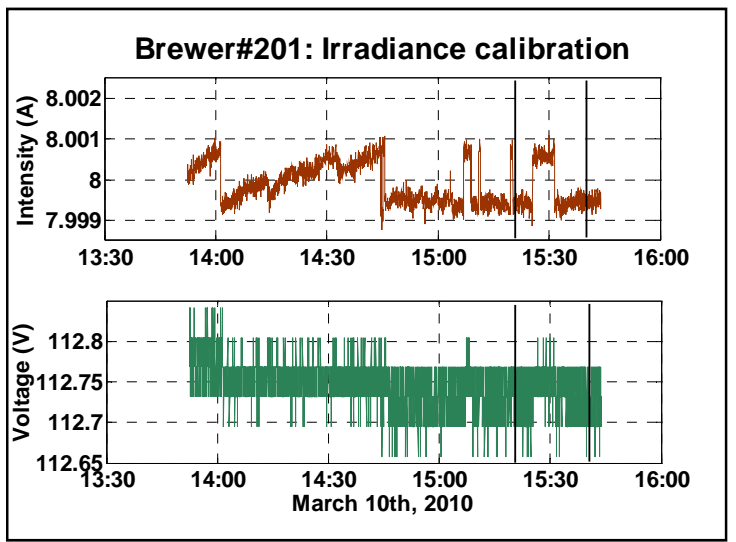

Fig. 8. Intensity and voltage applied to the lamp (vertical black lines show the interval time of calibration).

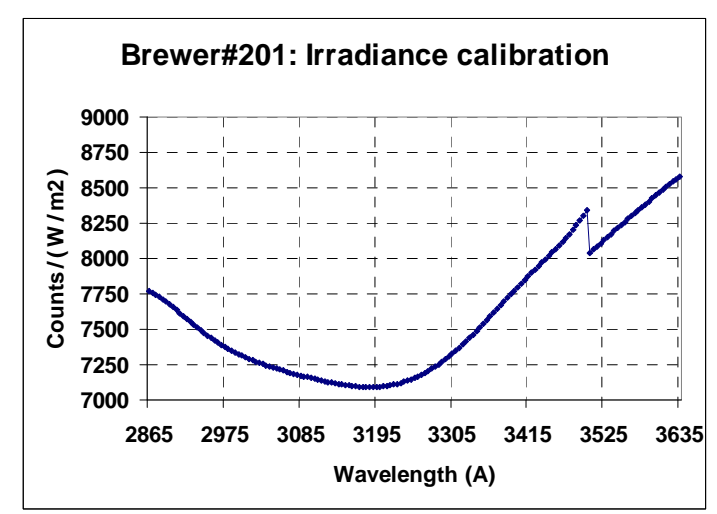

Fig. 9. UV response of the Brewer\#201. The "break" at about $3500 \AA$ is due to a change in the position of the slitmask to measure the larger wavelengths.

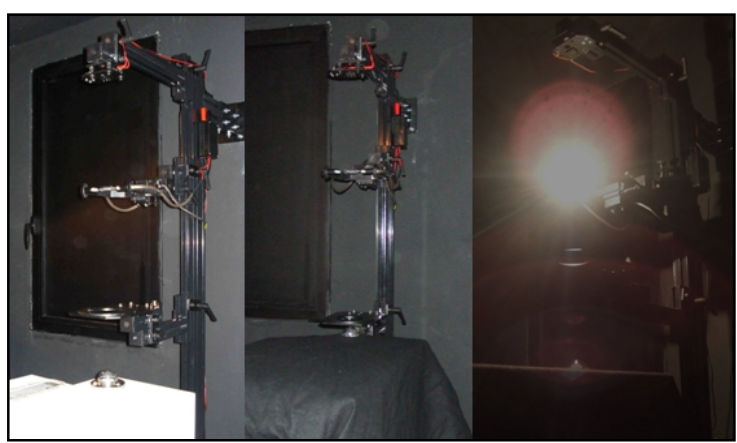

Fig. 10. Several steps of the irradiance calibration of the Brewer\#201.

\section{Conclusions}

A new optical calibration facility is available at the Izaña Observatory. At present, six set-ups have been developed for the absolute, spectral and cosine response calibration of the radiation measuring instruments installed at IZO. This facility allows a better Quality Assurance \& Quality Control of the radiation measurements. The systems are used for periodical calibrations of radiometers, spectroradiometers and sunphotometers involved in research activities within GAW, NDACC, BSRN, AERONET and RBCC-E programmes. 


\section{Acknowledgements}

This work was developed within the Specific Agreement of Collaboration between the University of Valladolid and the CIAI-AEMET "Establish methodologies and quality assurance systems for programs of photometry, radiometry, atmospheric ozone and aerosols within the atmospheric monitoring program of the World Meteorological Organization. Financial supports from the Spanish MICIIN (ref. CGL2008-05939-CO3-00/CLI and CGL 200909740) and from the GR-220 Project of the Junta de Castilla y León are gratefully acknowledged. 